\title{
Sleep deprivation: health consequences and societal impact
}

\author{
Mary A. Carskadon, $\mathrm{PhD}^{\mathrm{a}, \mathrm{b}, *}$ \\ ${ }^{a}$ Psychiatry and Human Behavior, Brown Medical School, 1011 Veterans Memorial Parkway, \\ Providence, RI 02915, USA \\ ${ }^{\mathrm{b}}$ Sleep Research Laboratory, E.P. Bradley Hospital, 300 Duncan Drive, East Providence, \\ RI 02906, USA
}

The impact of sleep deprivation can be incurred at many levels, including individual, family, community, and nations at large. In general, the societal impact falls within the spheres of transportation safety, health, and education. This brief article highlights certain recent findings and concerns.

\section{Transportation safety}

The single most pervasive area wherein the issue of sleep deprivation and the public weal intersect is that of transportation. The romantic image of old Dobbins safely guiding a sleepily bemused or sodden buggy rider homeward may or may not bear scrutiny. For certain, however, the twentieth-century emergence of multi-horse-powered juggernauts, directionless save for a human consciousness at the helm, finds us at a crossroads where alertness is requisite. As the speed, power, and numbers of vehicles increase, so too grows the need for a steady hand and eye attending to the task of safely navigating the roadways.

Many investigators have demonstrated the hazards of sleepy steering, typically characterizing the sleepy noncommercial auto driver as primarily young adult, usually male, and driving late at night or early in the morning, unable to ward off the spell of Morpheus, though at life's peril. Numerous assessments in the United States and abroad implicate sleep deprivation as a significant risk factor for crashes [1-7]. For example, Pack and colleagues [3] analyzed 1990-1992 data from the University of North Carolina's

* Psychiatry and Human Behavior, Brown Medical School, 1011 Veterans Memorial Parkway, Providence, RI 02915.

E-mail address: mary_carskadon@brown.edu 
Highway Safety Research Center to identify which characteristics were common in drivers who crashed when asleep. The data set included 4333 sleep-related crashes not associated with intoxication. Crashes tended to cluster during the overnight hours (approximately midnight to 7:00 AM) and the afternoon (approximately 3:00 PM), both of which have been associated with high vulnerability for sleepiness. Perhaps the most relevant finding visà-vis sleep deprivation was that the preponderance of the incidents occurred with a driver under the age of 25 years, an age at which poor sleep hygiene often leads to insufficient sleep.

Philip and colleagues [8] have confirmed some of the characteristics of sleepy drivers; for example, they examined drivers who, sleepless before a holiday excursion, were manifestly sleepy on the road. In this experiment, over 100 summertime drivers who stopped at a rest area were surveyed, gave sleepiness ratings, and underwent a two-nap sleep test. Nearly $90 \%$ of these drivers reported losing a significant amount of sleep during the 24 hours before their trip started, and compared with a control group, they fell asleep faster and slept longer on the two-nap sleep test. In another study, this group [4] surveyed over 2000 drivers stopped at random at toll booths in two French cities. Nearly all agreed to participate, and approximately 50\% reported sleep reduction from their usual level in the previous 24 hours. The risk factors associated with such a sleep debt included age (younger individuals had a greater sleep debt), reason for driving (commuters), distance driven (longer), time of the trip (beginning at night), phase preference (evening type), usual sleep length (long sleepers), and weekend sleep pattern (oversleeping).

Other investigators using different methodologies largely confirm these general findings. For example, McCartt and colleagues [6] performed a telephone survey of noncommercial drivers licensed in the state of New York. Over $50 \%$ of these drivers reported driving while drowsy, nearly one quarter said they had fallen asleep at the wheel without crashing, and nearly $5 \%$ had crashed either while drowsy or after having fallen asleep. As in the Pack study [3], the majority of crashes occurred during the overnight hours. A number of contributing factors for the fall-asleep crashes were identified, two of which likely precipitate significant sleep deprivation: nontraditional work hours (multiple jobs and rotating or night shift work) and poor sleep patterns (low nocturnal sleep time, poor quality sleep, and self-assessed insufficient sleep).

One interesting approach to evaluating the "cost" of sleep deprivation and driving is found in attempts to equate sleep deprivation with alcoholrelated driving impairment. Pack and colleagues [3] cite that the rate of fatalities in the fall-asleep crashes under investigation (1.4\%) was not far different from the fatality rate in crashes related to alcohol intoxication $(2.1 \%)$. Powell and colleagues [1] took the comparison one step further by examining actual driving performance in individuals under conditions of sleep loss (either following one night without sleep or losing 2 hours of sleep 
a night for a week) in comparison to driving with significant blood alcohol levels (mean $=.089 \mathrm{~g} / \mathrm{dL}$ ). Performance impairment for both sleep loss conditions and alcohol intoxication was significant and of comparable magnitude, and the authors concluded that the risks of driving while sleep deprived are "at least as dangerous" as when driving at an illegal level of alcohol intoxication.

Individuals and lobbying organizations in the United States are attempting to influence legislation to make it possible to prosecute individual drivers who cause crashes as a result of sleepiness caused by sleep deprivation. Indeed, one state has recently implemented legislation ("Maggie's Law"), raising the culpability for "fatigued" drivers to the level of reckless driving [9].

Automobile drivers share the road with others who are prone to fall prey to sleep deprivation's effects behind the wheel. One such group are long-haul truck drivers, who may often be short on sleep. Mitler and colleagues [10] provide one of a number of reports [11-13] describing the sleep-inducing stowaways infiltrating trips with many long-haul truckers - sleep debt, sleep disorders, nighttime sleep susceptibility - all acting in concert with truckers' demanding schedules to leave open the inevitability of disaster for some. When truckers were evaluated with close observation including electrophysiologic monitoring and performance testing, they slept far less than their self-reported sleep need. Actual sleep time averaged across 5 days was on average only about 4.8 hours per 24 hours. Furthermore, stage 1 sleep was recorded in 2 of 80 while driving, and video-rated drowsiness episodes lasting at least 6 minutes occurred in over half of the drivers (56\%). In this study, as in the studies of noncommercial drivers, the most vulnerable time occurred in the overnight/early morning hours.

Other forms of transportation, including railway and aviation, are not immune to the effects of sleep deprivation. One early electrophysiologic study in the field was performed by Torsvall and Akerstedt [14] in train drivers who repeated a 4.5-hour trip, once in the daylight and once during dark hours. Four of 11 drivers stated they had dozed off during the nighttime trip, and two entirely failed to react to signals. The electroencephalogram analyses showed more sleep-related phenomena in darkness than in daylight and more obvious signs of sleep and drowsiness in the train drivers who rated themselves as most sleepy. As to aviation, jet lag over many time zones, trips with multiple segments, and flying the "back side of the clock" are factors that carry a major risk for operational lapses due to sleep deprivation in pilots and crews [15-23]. As with ground-based drivers, pilots show greatest fatigue as the length of the trip is extended; indeed, the worst signs of fatigue (manifesting in such measures as electroencephalograms and vigilance) occurred during consecutive night flights [15,16]. Gander and colleagues [18-23] examined not only long-haul flight crews but also those involved in short-haul fixed-wing, short-haul helicopter, and domestic overnight cargo flying. Given a significant level of sleep loss across 
all of these domains, increasing sleepiness across days was predictable in the majority of the crew members. Especially in the overnight cargo crews, exacerbating the performance-eroding effects of sleep deprivation is the challenge created by much of the flying time occurring at the circadian phase associated with greatest declines in alertness and performance, independent of sleep loss. Air traffic controllers, as well, can show impaired performance resulting from sleepiness and fatigue; one study by Luna and colleagues [24] clearly related these difficulties to an unusual pattern of shift work scheduling. Acknowledgment of such risks has led to calls for interventions, often including hours of service limitations, to alleviate sleepiness and fatigue as risks for transportation disasters $[6,25,26]$.

Certain mishaps have brought attention that is greater than the single event - as in the case of the Exxon Valdez or the Challenger space shuttlewhere the loss of sleep for a key member of the system (the crew piloting the ship or the go/no-go decision makers) sets off a chain reaction that destroys a wilderness habitat or brings a nation to its knees in mourning. Yet with every transportation sleepiness event - from the death of a famed hockey coach on a lonely stretch of Midwest highway to the loss of a son/brother/ friend in the wee morning hours on a Connecticut interstate thoroughfareeach event takes an enormous personal toll in addition to the societal costs.

\section{Health}

The health-related costs of sleep deprivation are slowly emerging, as scientists begin to apply multidisciplinary tools to examine the role of insufficient sleep. The immune system has long been thought to be a vulnerable target for sleep deprivation's ill effects. Forever have grandmothers warned about the ill consequences of inadequate sleep; in the same breath, of course, other warnings of greater or lesser authenticity have emerged. Thus sleep scientists remained mute on sleep loss and immune function for many years. Krueger and Majde [27] and other basic scientists began to jumpstart a renewed interest in immune functions' ties to sleep with the identification of a variety of "sleep factors," many of which are those that arise in the immune cascade. Krueger and Majde propose that cytokine proteins synthesized by the immune system play a role in normal sleep regulation (increasing non-rapid eye movement sleep and decreasing rapid eye movement sleep) and that during inflammatory events, the increase in cytokine levels also intensifies this sleep regulatory effect. Furthermore, these events are also intertwined with hypothalamic neuropeptide systems, such as growth hormone-releasing hormone and corticotropin-releasing hormone. Grandmothers' admonitions, of course, worked from a more direct set of assumptions regarding sleep loss: if you do not get enough sleep, you will get sick. Investigators are now beginning to unravel some links 
between sleep and immune function, though the current state-of-the-art has yet to confirm the certainty of the predictions of grandmothers [28-35]. Nevertheless, acute and chronic sleep deprivation show evidence of immune changes, such as lowered titers following influenza immunization [35], decreased proportion of natural killer cells [29], reduced lymphokineactivated killer activity, reduced interleukin-2 production during sleep deprivation [31], and lower natural killer cell numbers in association with disrupted sleep in bereaved and depressed persons [30].

Another health link of sleep deprivation is to endocrine function, metabolic function, and obesity. Van Cauter and colleauges [36-39] have been prominent in revealing neuroendocrine and metabolic alterations in response to sleep restriction and "sleep debt" in adults. For example, acute and partial sleep deprivation both alter the normal pattern of cortisol release and can contribute to an alteration of "negative glucocorticoid feedback regulation [36]." Altered glucose tolerance and insulin resistance have also been associated with sleep deprivation or sleep restriction [38,39]. Links to diabetes, metabolic syndrome, and obesity as a result of insufficient or disrupted sleep (eg, sleep apnea syndromes) are emerging but are not fully established [40-44]. Even in adolescents, one study [45] has uncovered a potential association of poor sleep to obesity, albeit in this case the link is made somewhat indirectly through a reduction in daytime activity associated with disturbed sleep. Thus those youngsters with greater sleep disruption also demonstrated lowered activity in the daytime (measured actigraphically) and manifested a higher likelihood toward obesity; indeed, "for each hour of lost sleep, the odds of obesity increased by $80 \%$ " [45].

\section{Education}

Another, perhaps less directly obvious health-related association comes from issues that arise in medical training and the sleep deprivation that has long been inherent during this training [46-49]. For example, Baldwin and colleagues [46] recently reported a survey of first- and second-year residents in which the average number of duty hours per week was 83 for residents in year one and 76.2 in year 2; over half of the first-year residents were on duty more than 80 hours a week. Furthermore, residents' reports revealed a strong correlation between work hours and their stress level and hours of sleep. As to the negative effects of sleep deprivation on training and performance of medical residents, this area of investigation has been fraught with controversy and mixed findings [50-52]. Several studies, using a mixture of methods including self-report, neurobehavioral tests, and simulated medical procedures, revealed no or minimal effects of short sleep (usually indexed by post-call status) [50,53], whereas others detect significant deficits [51,52]. Howard and colleagues [54] found that residents were just as sleepy (by Multiple Sleep Latency Test [MSLT]) on baseline and post-call but were 
nominally alert when given the opportunity for extended sleep; this finding argues that performance decrements may not be seen when comparing postcall residents with residents under nominal conditions, because the sleep deprivation effects persist beyond the immediate post-call night. One finding that is apparent from virtually all of the studies of resident medical training is that increased hours of work are associated with decreased time spent sleeping and increased perceived fatigue and stress. In response to a number of these concerns, the Accreditation Council for Graduate Medical Education (ACGME) has recently revised their standards for resident training hours at work, including limiting duty hours to a maximum of 80 per week averaged over 4 weeks, no duty shifts lasting longer than 24 hours, and so forth [55]. The debate is ongoing about the efficacy of this regulatory strategy and the approaches used to comply, as well as the ability of the ACGME to monitor compliance [46,56-58]; however, the new standards signify a growing acceptance of the difficulties that sleep deprivation produces for effective educational efforts.

Such awareness is dawning at other levels of educational practice. Accumulated evidence of chronic sleep restriction in adolescents due to behavioral, psychosocial, and intrinsic biologic processes [59,60] led an effort initially spearheaded by members of the Minnesota Medical Association [61] to restrict the early timing of school days. Hundreds of school districts have considered this issue over the last decade or so, but no formal registry exists. Our group recently surveyed 345 randomly selected United States public schools serving grades 9 through 12 and found that $40 \%$ had changed or contemplated changing start times in the years between 1999 and 2002 [62]. Representative Zoe Lofgren of California has repeatedly sponsored legislation to encourage school districts to move high school starting times to a later hour to enable teens to get adequate sleep (the "ZZZ's to A's" Act) [63]. Despite the urging of medical associations, advocacy groups (eg, the National Sleep Foundation), and even legislative efforts, such changes have come slowly because of the nature of the local control of school schedules and the often acrimonious debates that occur in individual communities. Stakeholders in the issue are diverse, as recently summarized by Wahlstrom [64], yet a change can have positive outcomes in areas such as attendance, tardiness, improved mood, and graduation rates [65].

One instance in which change occurred in response to a large body of evidence implicating sleep loss as well as circadian phase shifts of adolescents with poor outcomes [66-68] was when the US Navy changed the sleep schedules for recruits in training at the US Navy Recruit Training Command in Great Lakes, Illinois. The change, implemented in 2002, resulted in a change from sleeping hours of 2200 to 0400 to sleeping hours of 2200 to 0600 . This effort has been recognized by the National Sleep Foundation as its 2004 Healthy Sleep Community Award [69]. The fact that the US Navy hierarchy could virtually overnight provide the nearly 60,000 
young men and women who undergo training at this facility each year with the opportunity to sleep significantly longer and later than previous years' recruits stands in stark contrast to the slow gains made by community school boards struggling to decide to delay the school start time.

\section{Summary}

Sleep deprivation can have significant consequences, and society's responses to the structural issues that contribute to sleep deprivation-as well as ill-time sleeping and waking - take many forms. The success of such efforts as hours of service regulations, standards for residency duty hours, and recommendations for school starting times has been mixed. The full story has not been written, nor can we likely anticipate that all of the risks inherent in sleep loss will ever be eliminated. The next challenges are to determine with clarity the severity of the risks of sleep deprivation and the benefits of added wakefulness. The most difficult task will be determining on an individual basis who is or is not at risk and what countermeasures are appropriate.

\section{References}

[1] Powell NB, Schechtman KB, Riley RW, Li K, Troell R, Guilleminault C. The road to danger: the comparative risks of driving while sleepy. Laryngoscope 2001;111:887-93.

[2] Stutts JC, Wilkins JW, Scott Osberg J, Vaughn BV. Driver risk factors for sleep-related crashes. Accid Anal Prev 2003;35:321-31.

[3] Pack AI, Pack AM, Rodgman E, Cucchiara A, Dinges DF, Schwab CW. Characteristics of crashes attributed to the driver having fallen asleep. Accid Anal Prev 1995;27:769-75.

[4] Philip P, Taillard J, Guilleminault C, Quera Salva MA, Bioulac B, Ohayon M. Long distance driving and self-induced sleep deprivation among automobile drivers. Sleep 1999; 22:475-80.

[5] Cummings P, Koepsell TD, Moffat JM, Rivara FP. Drowsiness, counter-measures to drowsiness, and the risk of a motor vehicle crash. Inj Prev 2001;7:194-9.

[6] McCartt AT, Ribner SA, Pack AI, Hammer MC. The scope and nature of the drowsy driving problem in New York State. Accid Anal Prev 1996;28:511-7.

[7] Carter N, Ulfberg J, Nystrom B, Edling C. Sleep debt, sleepiness and accidents among males in the general population and male professional drivers. Accid Anal Prev 2003;35: $613-7$.

[8] Philip P, Ghorayeb I, Leger D, Menny JC, Bioulac B, Dabadie P, et al. Objective measurement of sleepiness in summer vacation long-distance drivers. Electroencephalogr Clin Neurophysiol 1997;102:383-9.

[9] Geist GF, Merkt R, Altamuro S. An act concerning vehicular homicide and amending N.J.S.2C:11-5. State of New Jersey. Available at: http://www.njleg.state.nj.us/2002/Bills/ A1500/1347_R2.HTM. Accessed February 22, 2004.

[10] Mitler MM, Miller JC, Lipsitz JJ, Walsh JK, Wylie CD. The sleep of long-haul truck drivers. N Engl J Med 1997;337:755-61.

[11] Balkin T, Thome D, Sing H, Thomas M, Redmond N, Wesenstein N, et al. Effects of sleep schedules on commercial motor vehicle driver performance. Washington, DC: Department of Transportation Federal Motor Carrier Safety Administration; 2000. Publication no. DOT-MC-00-133. 
[12] Wylie CD, Shultz T, Miller JC, Mitler MM, Mackie RR. Commercial motor vehicle driver fatigue and alertness study: project report. Washington, DC: Federal Highway Administration; 1996. Publication no. FHWA-MC-97-002.

[13] Stoohs RA, Bingham LA, Itoi A, Guilleminault C, Dement WC. Sleep and sleepdisordered breathing in commercial long-haul truck drivers. Chest 1995;107:1275-82.

[14] Torsvall L, Akerstedt T. Sleepiness on the job: continuously measured EEG changes in train drivers. Electroencephalogr Clin Neurophysiol 1987;66:502-11.

[15] Samel A, Wegmann HM, Vejvoda M. Aircrew fatigue in long-haul operations. Accid Anal Prev 1997;29:439-52.

[16] Samel A, Wegmann HM, Vejvoda M, Drescher J, Gundel A, Manzey D, et al. Two-crew operations: stress and fatigue during long-haul night flights. Aviat Space Environ Med 1997;68:679-87.

[17] Caldwell JA Jr. Fatigue in the aviation environment: an overview of the causes and effects as well as recommended countermeasures. Aviat Space Environ Med 1997;68:932-8.

[18] Gander PH, Rosekind MR, Gregory KB. Flight crew fatigue VI: a synthesis. Aviat Space Environ Med 1998;69(Suppl 9):B49-60.

[19] Gander PH, Gregory KB, Miller DL, Graeber RC, Connell LJ, Rosekind MR. Flight crew fatigue V: long-haul air transport operations. Aviat Space Environ Med 1998;69(Suppl 9): B37-48.

[20] Gander PH, Gregory KB, Connell LJ, Graeber RC, Miller DL, Rosekind MR. Flight crew fatigue IV: overnight cargo operations. Aviat Space Environ Med 1998;69(Suppl 9): B26-36.

[21] Gander PH, Barnes RM, Gregory KB, Graeber RC, Connell LJ, Rosekind MR. Flight crew fatigue III: North Sea helicopter air transport operations. Aviat Space Environ Med 1998;69(Suppl 9):B16-25.

[22] Gander PH, Gregory KB, Graeber RC, Connell LJ, Miller DL, Rosekind MR. Flight crew fatigue II: short-haul fixed-wing air transport operations. Aviat Space Environ Med 1998; 69(Suppl 9):B8-15.

[23] Gander PH, Graeber RC, Connell LJ, Gregory KB, Miller DL, Rosekind MR. Flight crew fatigue I: objectives and methods. Aviat Space Environ Med 1998;69(Suppl 9): B1-7.

[24] Luna TD, French J, Mitcha JL. A study of USAF air traffic controller shiftwork: sleep, fatigue, activity, and mood analyses. Aviat Space Environ Med 1997;68:18-23.

[25] Rosekind MR, Gander PH, Gregory KB, Smith RM, Miller DL, Oyung R, et al. Managing fatigue in operational settings 2: an integrated approach. Behav Med 1996;21: $166-70$.

[26] Goode JH. Are pilots at risk of accidents due to fatigue? J Safety Res 2003;34:309-13.

[27] Krueger JM, Majde JA. Humoral links between sleep and the immune system: research issues. Ann N Y Acad Sci 2003;992:9-20.

[28] Toth LA, Rehg JE. Effects of sleep deprivation and other stressors on the immune and inflammatory responses of influenza-infected mice. Life Sci 1998;63:701-9.

[29] Ozturk L, Pelin Z, Karadeniz D, Kaynak H, Cakar L, Gozukirmizi E. Effects of 48 hours sleep deprivation on human immune profile. Sleep Res Online 1999;2:107-11.

[30] Hall M, Baum A, Buysse DJ, Prigerson HG, Kupfer DJ, Reynolds CF III. Sleep as a mediator of the stress-immune relationship. Psychosom Med 1998;60:48-51.

[31] Irwin M, McClintick J, Costlow C, Fortner M, White J, Gillin JC. Partial night sleep deprivation reduces natural killer and cellular immune responses in humans. FASEB J 1996;10:643-53.

[32] Moldofsky H. Sleep and the immune system. Int J Immunopharmacol 1995;17:649-54.

[33] Dinges DF, Douglas SD, Hamarman S, Zaugg L, Kapoor S. Sleep deprivation and human immune function. Adv Neuroimmunol 1995;5:97-110.

[34] Benca RM, Kushida CA, Everson CA, Kalski R, Bergmann BM, Rechtschaffen A. Sleep deprivation in the rat: VII. Immune function. Sleep 1989;12:47-52. 
[35] Spiegel K, Sheridan JF, Van Cauter E. Effect of sleep deprivation on response to immunization. JAMA 2002;288:1471-2.

[36] Leproult R, Copinschi G, Buxton O, Van Cauter E. Sleep loss results in an elevation of cortisol levels the next evening. Sleep 1997;20:865-70.

[37] Leproult R, Van Reeth O, Byrne MM, Sturis J, Van Cauter E. Sleepiness, performance, and neuroendocrine function during sleep deprivation: effects of exposure to bright light or exercise. J Biol Rhythms 1997;12:245-58.

[38] Van Cauter EV, Polonsky KS, Blackman JD, Roland D, Sturis J, Byrne MM, et al. Abnormal temporal patterns of glucose tolerance in obesity: relationship to sleep-related growth hormone secretion and circadian cortisol rhythmicity. J Clin Endocrinol Metab 1994;79:1797-805.

[39] Spiegel K, Leproult R, Van Cauter E. Impact of sleep debt on metabolic and endocrine function. Lancet 1999;354:1435-9.

[40] Lanfranco F, Gianotti L, Maccario M. Endocrine and metabolic alterations in obstructive sleep apnea syndrome. J Endocrinol Invest 2003;26:491-2.

[41] Tassone F, Lanfranco F, Gianotti L, et al. Obstructive sleep apnoea syndrome impairs insulin sensitivity independently of anthropometric variables. Clin Endocrinol (Oxf) 2003; 59:374-9.

[42] Vgontzas AN, Bixler EO, Chrousos GP. Metabolic disturbances in obesity versus sleep apnoea: the importance of visceral obesity and insulin resistance. J Intern Med 2003;254: $32-44$.

[43] Brown LK. A waist is a terrible thing to mind: central obesity, the metabolic syndrome, and sleep apnea hypopnea syndrome. Chest 2002;122:774-8.

[44] Ip MS, Lam B, Ng MM, Lam WK, Tsang KW, Lam KS. Obstructive sleep apnea is independently associated with insulin resistance. Am J Respir Crit Care Med 2002;165: 670-6.

[45] Gupta NK, Mueller WH, Chan W, Meininger JC. Is obesity associated with poor sleep quality in adolescents? Am J Hum Biol 2002;14:762-8.

[46] Baldwin DC Jr, Daugherty SR, Tsai R, Scotti MJ Jr. A national survey of residents' selfreported work hours: thinking beyond specialty. Acad Med 2003;78:1154-63.

[47] Defoe DM, Power ML, Holzman GB, Carpentieri A, Schulkin J. Long hours and little sleep: work schedules of residents in obstetrics and gynecology. Obstet Gynecol 2001;97: $1015-8$.

[48] Owens JA. Sleep loss and fatigue in medical training. Curr Opin Pulm Med 2001;7:411-8.

[49] Sawyer RG, Tribble CG, Newberg DS, Pruett TL, Minasi JS. Intern call schedules and their relationship to sleep, operating room participation, stress, and satisfaction. Surgery 1999; 126:337-42.

[50] Browne BJ, Van Susteren T, Onsager DR, Simpson D, Salaymeh B, Condon RE. Influence of sleep deprivation on learning among surgical house staff and medical students. Surgery 1994;115:604-10.

[51] Eastridge BJ, Hamilton EC, O'Keefe GE, Rege RV, Valentine RJ, Jones DJ, et al. Effect of sleep deprivation on the performance of simulated laparoscopic surgical skill. Am J Surg 2003;186:169-74.

[52] Howard SK, Gaba DM, Smith BE, Weinger MB, Herndon C, Keshavacharya S, et al. Simulation study of rested versus sleep-deprived anesthesiologists. Anesthesiology 2003;98: 1345-55 [discussion: 1345A].

[53] Bartle EJ, Sun JH, Thompson L, Light AI, McCool C, Heaton S. The effects of acute sleep deprivation during residency training. Surgery 1988;104:311-6.

[54] Howard SK, Gaba DM, Rosekind MR, Zarcone VP. The risks and implications of excessive daytime sleepiness in resident physicians. Acad Med 2002;77:1019-25.

[55] Accreditation Council for Graduate Medical Education. ACGME duty hours standards now in effect for all residency programs. Available at: http://www.acgme.org. Accessed February 22, 2004. 
[56] Steinbrook R. The debate over residents' work hours. N Engl J Med 2002;347:1296-302.

[57] Whetsell JF. Changing the law, changing the culture: rethinking the "sleepy resident" problem. Ann Health Law 2003;12:23-73.

[58] Cavallo A, Ris MD, Succop P. The night float paradigm to decrease sleep deprivation: good solution or a new problem? Ergonomics 2003;46:653-63.

[59] Carskadon MA. Adolescent sleepiness: increased risk in a high-risk population. Alcohol Drugs Driving 1990;5/6:317-28.

[60] Carskadon MA. Patterns of sleep and sleepiness in adolescents. Pediatrician 1990;17:5-12.

[61] Adolescent Sleep Deprivation Educational Campaign. Minnesota Medical Association. Available at: http://www.mmaonline.net/policycomp/SubResults.cfm?section $=300.11$. Accessed February 22, 2004.

[62] Wolfson AR, Carskadon MA. A survey of factors influencing high school start times. NASSP Bulletin. 2004. Submitted for publication.

[63] Lofgren Z. ZZZ's to A's. Available at: http://zoelofgren.house.gov/congress/z2a.htm. Accessed February 22, 2004.

[64] Wahlstrom K. Accommodating the sleep patterns of adolescents within current educational structures: an uncharted path. In: Carskadon MA, editor. Adolescent sleep patterns: biological, sociological, and psychological influences. Cambridge (UK): Cambridge University Press; 2002. p. 172-97.

[65] Wahlstrom K. Changing times: Findings from the first longitudinal study of later high school start times. NASSP Bulletin 2002;86:3-21.

[66] Wolfson AR, Carskadon MA. Sleep schedules and daytime functioning in adolescents. Child Dev 1998;69:875-87.

[67] Carskadon MA, Wolfson AR, Acebo C, Tzischinsky O, Seifer R. Adolescent sleep patterns, circadian timing, and sleepiness at a transition to early school days. Sleep 1998; 21:871-81.

[68] Carskadon MA. Factors influencing sleep patterns of adolescents. In: Carskadon MA, editor. Adolescent sleep patterns: biological, social, and psychological influences. Cambridge (UK): Cambridge University Press; 2002. p. 4-26.

[69] Healthy Sleep Community Award. Available at: http://www.sleepfoundation.org/NSAW/ community.cfm. Accessed March 29, 2004. 